\title{
A Novel Approach to Alveolar Bone Complex Defects 3D Reconstruction
}

DOI: $10.17691 /$ stm2017.9.2.04

Received January 1, 2017

A.A. Muraev, MD, PhD, Associate Professor, Department of Maxillofacial Surgery and Implantology,

Faculty of Doctors' Advanced Training ${ }^{1}$; Associate Professor, Department of Maxillofacial Surgery

and Oral Surgery2;

Y.V. Gazhva, MD, PhD, Tutor, Department of Maxillofacial Surgery and Implantology,

Faculty of Doctors' Advanced Training';

S.G. Ivashkevich, MD, PhD, Tutor, Department of Maxillofacial Surgery and Oral Surgery²;

V.M. Riabova, MD, PhD, Associate Professor, Department of Maxillofacial Surgery and Implantology,

Faculty of Doctors' Advanced Training ${ }^{1}$;

N.L. Korotkova, MD, DSc, Associate Professor, Department of Maxillofacial Surgery and Implantology, Faculty of Doctors' Advanced Training';

Y.A. Semyonova, PhD Student, Department of Maxillofacial Surgery and Implantology,

Faculty of Doctors' Advanced Training ${ }^{1}$;

I.N. Metsuku, PhD Student, Department of Maxillofacial Surgery and Oral Surgery²;

R.L. Faizullin, Software Quality Assurance Lead';

S.Y. Ivanov, MD, DSc, Professor, Head of the Department of Maxillofacial Surgery, Faculty of Dentistry4; Head of the Department of Maxillofacial Surgery and Implantology, Faculty of Doctors' Advanced Training ${ }^{1}$

${ }^{1}$ Nizhny Novgorod State Medical Academy, 10/1 Minin and Pozharsky Square, Nizhny Novgorod, 603005,

Russian Federation;

${ }^{2}$ The Peoples' Friendship University of Russia, 6 Miklukho-Maklaya St., Moscow, 117198, Russian Federation;

${ }^{3}$ LLC "NEXT", 15/3 Rochdel'skaya St., Moscow, 123002, Russian Federation;

${ }^{4}$ I.M. Sechenov First Moscow State Medical University, 8/2 Trubetskaya St., Moscow, 119991,

Russian Federation

The aim of the investigation was to assess the efficacy of the 3D reconstruction of the alveolar bone by means of guided bone regeneration based on computer-assisted 3D planning using a resorbable dental membrane.

Materials and Methods. 35 practically healthy patients without a marked concomitant somatic pathology with a diagnosis of "partial teeth loss complicated by alveolar bone atrophy" took part in the study. All patients underwent reconstructive operations to eliminate the defects and restore the alveolar bone volume using guided bone regeneration procedure and resorbable dental membranes. Planning and operations were performed according to the developed unified protocol including computer-assisted 3D operation planning and fabrication of intraoperative templates for dental membranes using 3D prototyping.

Results. The developed method of computer-assisted 3D operation planning and fabrication of intraoperative templates for dental membranes using $3 \mathrm{D}$ prototyping has proved to be effective as it reduces the time of operative intervention, excludes the risk of forming a smaller membrane of inadequate shape, gives the required bone volume.

Conclusion. The proposed method of computer-assisted 3D operation planning and fabrication of intraoperative templates for dental membranes using 3D prototyping allows surgeons to improve the precision of the guided bone regeneration operations, to diminish the intraoperative time of membrane adaptation, and avoid the possibility of its mispositioning. At the same time, application of the resorbable dental membrane increases the efficacy of the 3D alveolar bone reconstruction.

Key words: alveolar bone reconstruction; guided bone regeneration; dental membranes for bone reconstruction; computer-assisted 3D planning; alveolar bone defects.

Reconstructive operations on gnathic bone tissues are aimed at the restoration of the adequate volume and quality of bone tissue for subsequent implantationprosthetic treatment $[1,2]$. The main causes of the width and height reduction of the maxilla alveolar process and the alveolar part of the mandible (further "alveolar bone") are bone resorption due to periodontitis, traumatic teeth extraction, and atrophy resulted from decreased functional load on the bone [3, 4].

In the literature, the terms "defect" and "deformity" are encountered to describe impairments in the jaw structure. The word "defect" (from Latin defectus -

For contacts: Alexander A. Muraev, e-mail: muraev@gmail.com 
flaw) has the meaning of "a flaw, drawback, shortage", whereas the word "deformation" (from Latin deformatio - distortion) designates alteration of dimensions and shape of the solid body under the action of external forces (usually without changes in its mass) [5]. Based on these definitions, it is expedient to refer congenital conditions (macro- and micrognathia) to the deformations of the jaws and alveolar bone, while all the acquired imperfections of the jaws due to teeth extraction, periodontitis, traumas, and atrophy should be referred to defects.

The most difficult cases for treatment are alveolar bone defects in several planes (horizontal or vertical). The authors have previously suggested various methods of $3 \mathrm{D}$ bone reconstruction using bone flaps (sandwich plasty by a rotation flap) and bone grafts (L-shaped plasty) [6-8]. Meanwhile, our experience showed that there are a number of clinical and anatomical conditions, in which application of the mentioned methods in not expedient. First of all, it is a marked degree of atrophy, which requires the horizontal and vertical bone volume increase by more than $5 \mathrm{~mm}$, though a sandwich plasty and veneer L-shaped plasty allow for the increase of the alveolar bone height only within $5 \mathrm{~mm}$. Application of these methods, e.g. sandwich plasty, can be impossible because of the absence of the initial bone volume (close location of the inferior alveolar nerve), and veneer plasty is impossible due to the great irregularities of the recipient bed when it is difficult to achieve adherence of the bone graft. Another restriction is additional traumaticity during bone graft harvesting when restoration of the bone defects is limited by 1-3 teeth. In the situations described, a guided bone regeneration procedure using dental membranes may be a method of choice. This method lacks the above-mentioned limitations, i.e. a bone defect is limited by a membrane determining the shape and volume of the reconstruction;

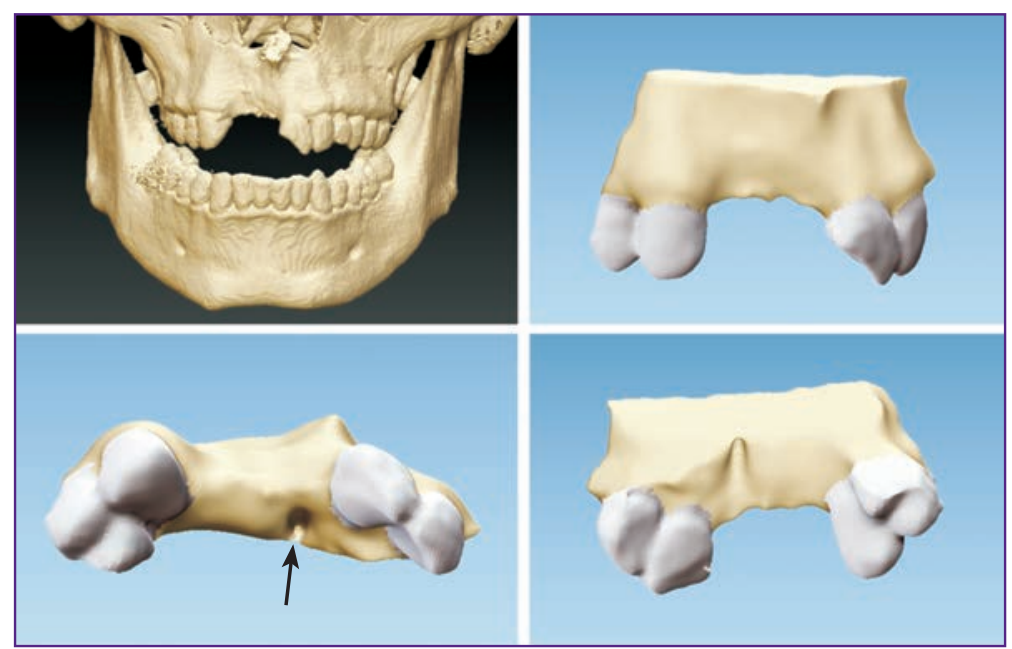

Figure 1. 3D computer model of the upper jaw fragment with the alveolar process defect in the projection of the missing teeth 1.2, 1.1 in different projections. The arrow shows the incisor canal the cavity formed by the membrane is filled by bone chips possessing all the merits of the autogenous bone [9], and bone hydroxyapatite, providing matrix properties for the bone regenerate [10]. Porous scaffolds [11-13] and microparticles from biodegradable polymers [14, 15], and biopolymer hydrogels [14] can be used as a material for filling the bone tissue defects as well as composite products and materials $[13,14]$ including those possessing therapeutic activity owing to the prolong release of the drugs loaded into polymer matrices [15, 16], while barrier membranes [16-18] can be fabricated from biodegradable $[19,20]$ and biocompatible polymers [21-24].

The main drawback of guided bone regeneration during the alveolar bone restoration is a difficulty of adaptation and stable fixation of the dental membrane limiting the reconstruction zone. The authors propose a method of computer-assisted three-dimensional guided bone regeneration planning based on X-ray computed tomography data in solving this problem.

The aim of the investigation was to assess the efficacy of three-dimensional reconstruction of the alveolar bone by means of guided bone regeneration based on computer-assisted 3D planning using a resorbable dental membrane.

Materials and Methods. 35 practically healthy patients without a marked concomitant somatic pathology with a diagnosis of "partial teeth loss complicated by alveolar bone atrophy" (according to ICD - K08.1, K08.2) were included in the study. There were 17 men and 18 women at the age of 35-62 years. All patients underwent reconstructive operations to eliminate the defects and restore the alveolar bone by means of guided bone regeneration using resorbable dental membranes (Lamina membrane; Osteobiol, Italy). 20 operations were performed on the lower jaw, and 15 on the upper one. Planning and operations were done according to the developed unified protocol.

The study complies with the Declaration of Helsinki (the Declaration was passed in June 1964, Helsinki, Finland and revised in October 2000, Edinburgh, Scotland) and was performed following approval by the Ethic Committee of Nizhny Novgorod State Medical Academy. Written informed consent was obtained from every patient.

Computer-assisted 3D operation planning. All patients underwent cone-beam computed tomography. If there were metalceramic orthopedic constructions on the teeth adhering to the area of the planning reconstruction, they were removed to reduce interferences during X-ray examination. On the basis of the obtained DICOM files a reformation of the $3 \mathrm{D}$ jaw model was performed (Figure 1), and thereafter a volume of the bone reconstruction was simulated using ViSurgery program (Russia) (Figure 2). 


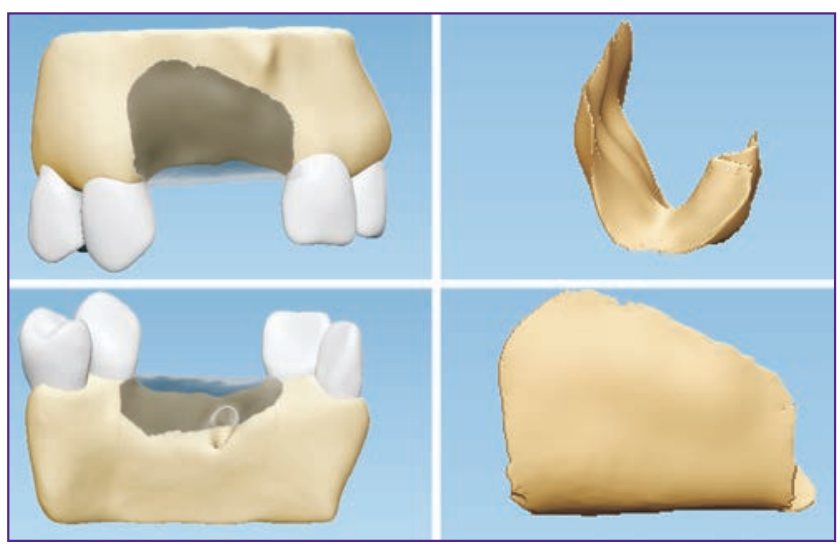

Figure 2. 3D computer model of the upper jaw fragment with the alveolar process defect in the projection of the missing teeth 1.2, 1.1 in different projections, and a 3D model of the reconstruction volume

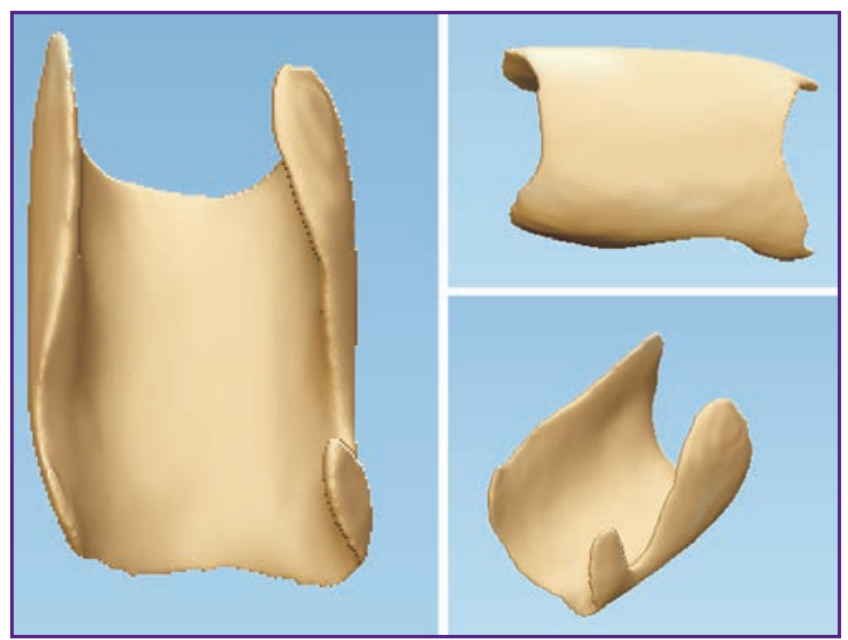

Figure 3. 3D computer model of the template for the dental membrane

Modeling of the regenerate upper border was done by the level of the bone tissue at the teeth cervices limiting the defect. In case of the terminal dentition defects, the level of reconstruction was determined by the precervical bone level of the distal tooth. The reconstruction volume was calculated with the help of the mentioned program (in $\mathrm{mm}^{3}$ ), this value was further compared to the bone volume obtained. Then, a template of the dental membrane was simulated using the same program (Figure 3).

3D model of the alveolar bone and a template of the dental membrane were printed on Engineer V2 3D printer ( ${ }^{3 D}$ Exprts.ru, Russia) (Figure 4) using a fused deposition modeling (FDM) technology. A polylactide wire was used for printing (a wire diameter of $1.75 \mathrm{~mm}$, a melting temperature of $225^{\circ} \mathrm{C}$, density of $1.08-1.2 \mathrm{~kg} / \mathrm{m}^{2}$, ecologically pure, nontoxic, produced by the Moscow plant FDPlast, Russia). A model layer thickness was $100 \mu \mathrm{m}$.
To control the precision of the virtual planning and $3 \mathrm{D}$ model printing, the extension of the bone defect was measured on the slices of the computed tomography and on the 3D jaw models, and the obtained values were compared (Figure 5). In each case, three repeated measurements were conducted on the tomogram and the model in order to determine the reproducibility of the method. The results obtained were statistically processed using SAS Studio software. Fisher's F-test and Student's t-test were applied. The values of mean absolute deviations of the results of bone defect

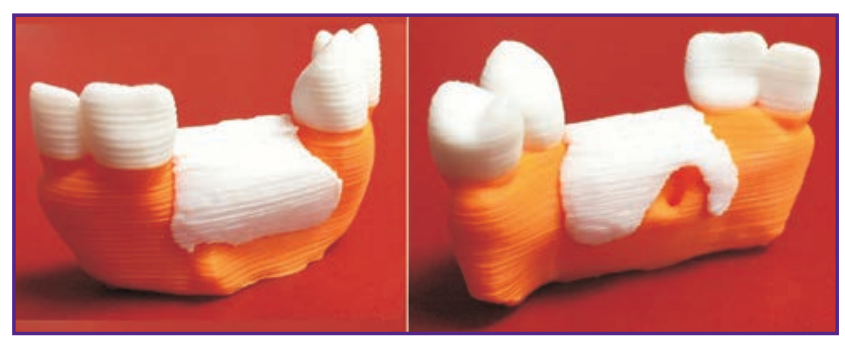

Figure 4. 3D model of the upper jaw fragment (orange) and a template for the dental membrane (white) printed on the 3D printer
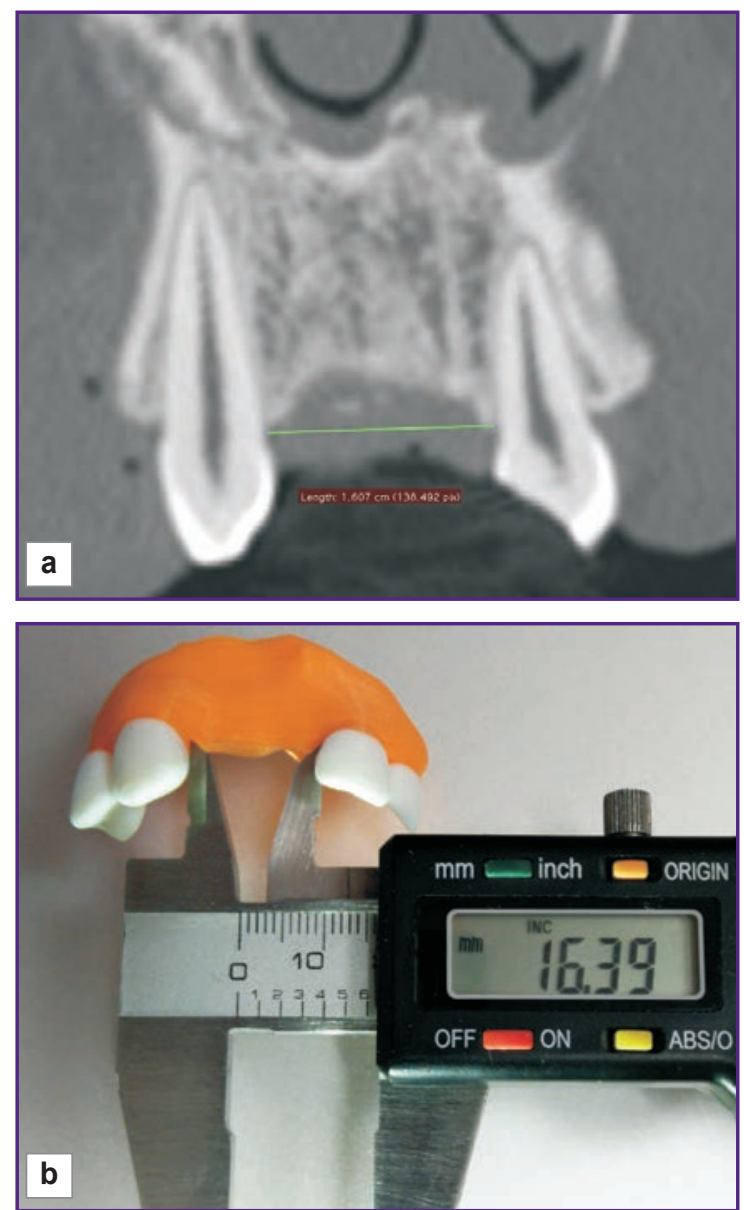

Figure 5. Measuring the extension of the bone defect/ reconstruction zone on the computed tomography slice (a) and the same distance on the printed 3D model (b) 
extension measurements according to the computed tomogram and 3D model was calculated by the formula:

$$
\frac{\sum_{i=1}^{10}|\overline{K T} i-3 \bar{D} i|}{10},
$$

where $\overline{K T} i$ is the $i^{\text {th }}$ measurement by the $\mathrm{CT}$ model, $3 \bar{D} i$ is the $i^{\text {th }}$ measurement by the $3 D$ model. The data obtained allow the comparison of the systematic measurement error, connected with the method of model transformation, with the measurement errors for each model.

The membrane template was sterilized and used during the operation to impart the required shape to the dental membrane limiting the reconstruction zone.

The protocol of 3D alveolar bone reconstruction. The operation for bone plasty was performed under the balanced anesthesia (Figure 6). Incision of the mucous membrane was made, the mucoperiosteal flap separated and the alveolar bone defect area skeletonized (Figure 7). Then, Lamina membrane (Osteobiol, Italy) and the sterilized template were superposed to impart the required shape to the membrane (Figure 8). From the palate site, the membrane was fixed by pins or micro screws (Konmet, Russia) (Figures 9, 10). Bone chips obtained from the

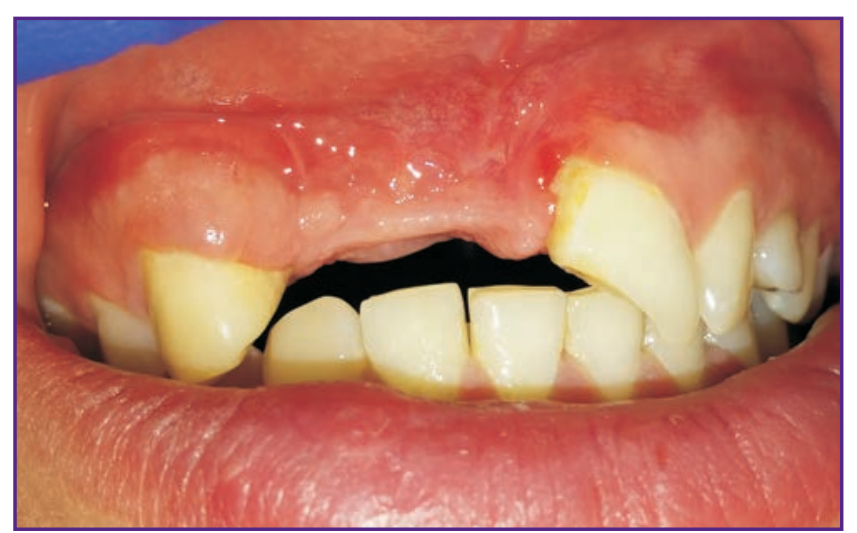

Figure 6. The oral cavity before treatment

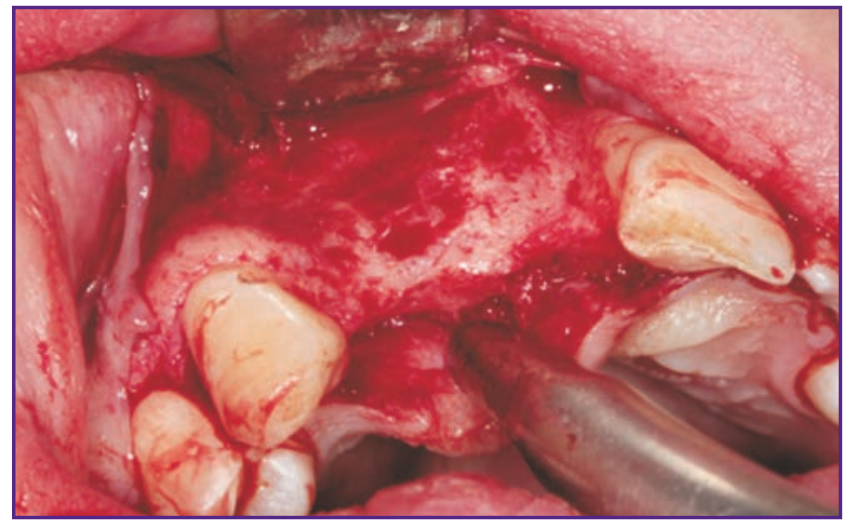

Figure 7. The upper jaw alveolar process is skeletonized

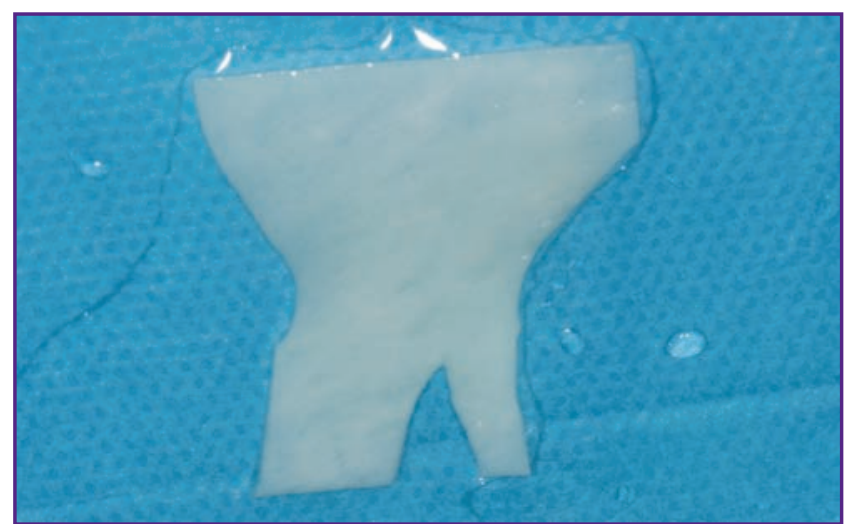

Figure 8. The dental membrane is cut using 3D template

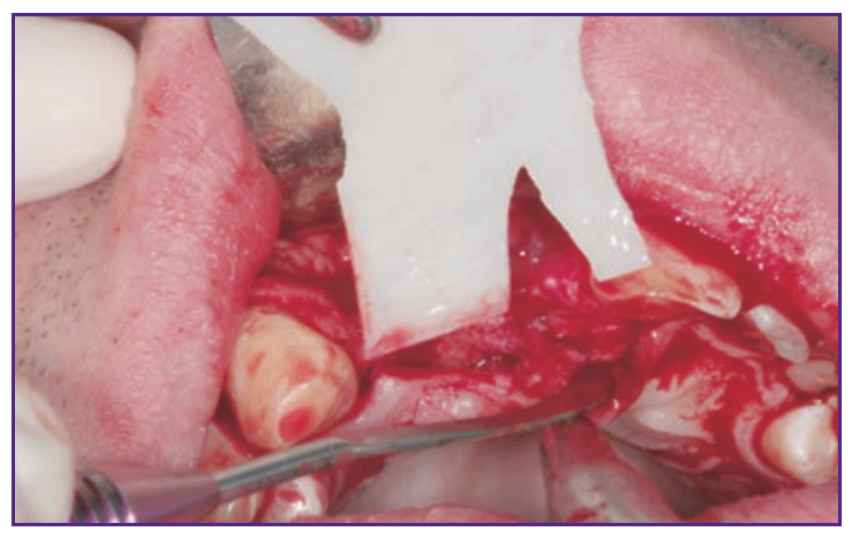

Figure 9. Introduction of the template-preadapted Lamina membrane. A cut was made in the membrane for the incisor opening and the nerve coming out of it

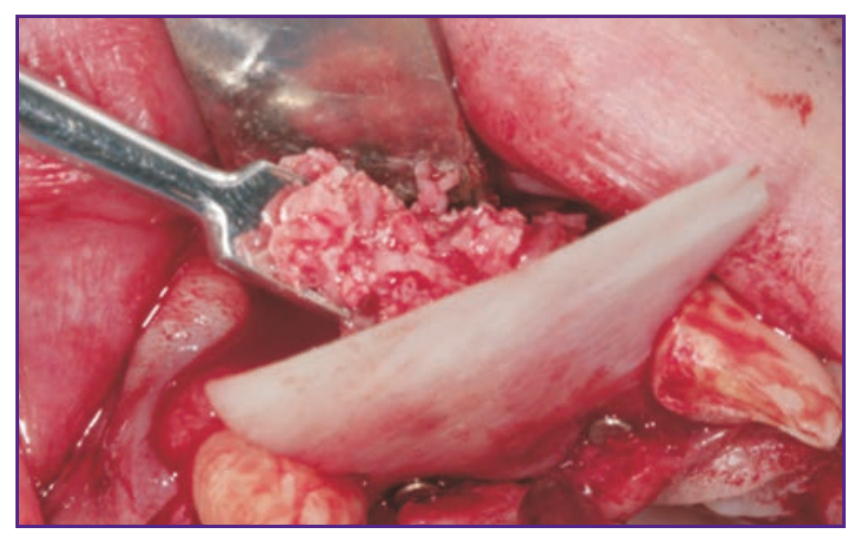

Figure 10. The membrane is fixed from the palatal surface with Konmet pins. The bone defect is filled with a mixture of bone chips and deproteinized xenogenic hydroxyapatite

oblique line of the mandible by a bone scraper were used as a material for the reconstruction. The chips were mixed with deproteinized bone hydroxyapatite (Bioplast-Dent; VladMiVa, Russia) in the ratio of 1:1. The obtained mass was placed in the defect area and compacted (See Figure 10). The reconstruction area 
Figure 11. The reconstruction zone is covered by the membrane. Pin fixation is done from the vestibular side
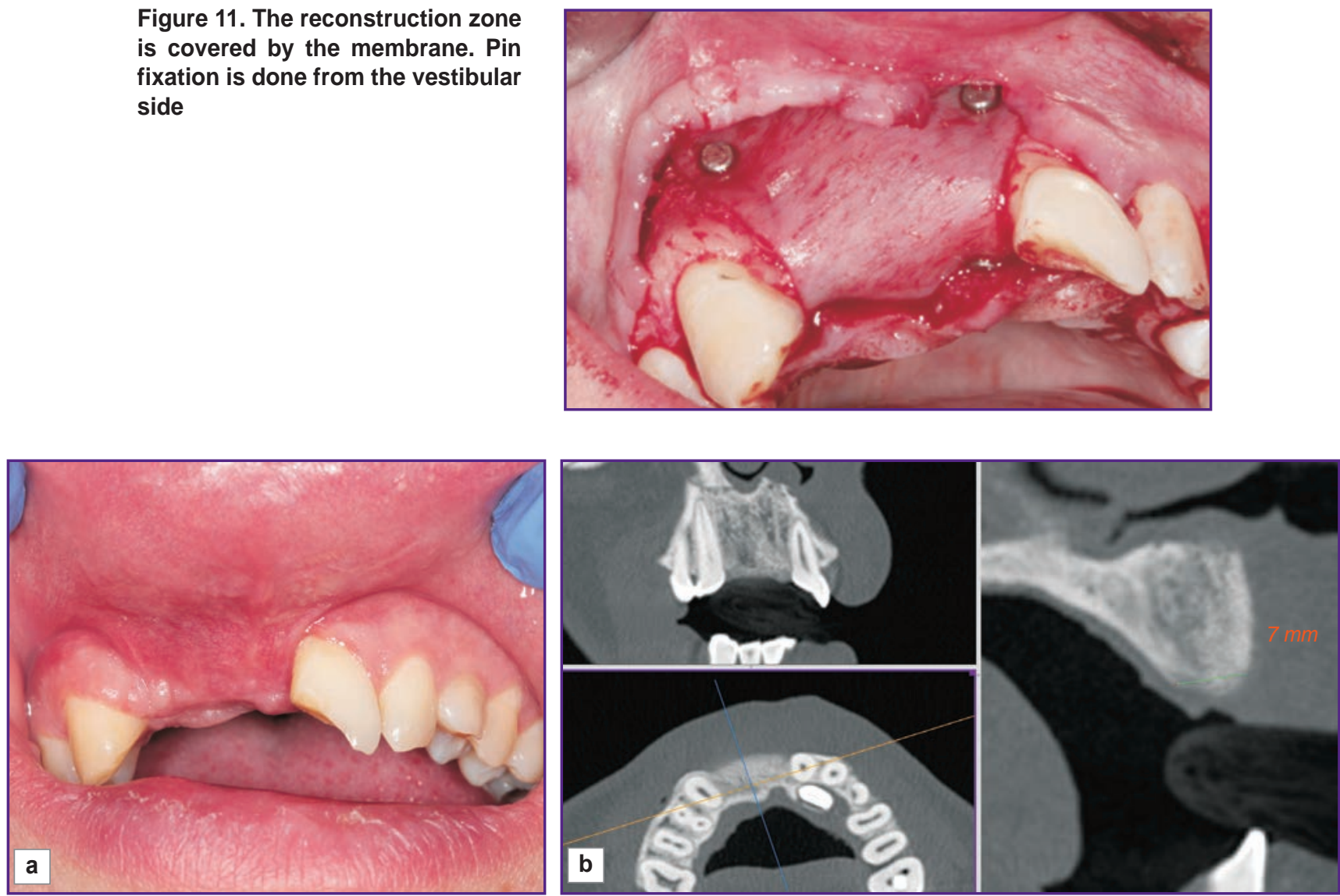

Figure 12. The oral cavity 8 months after the operation (a); computed tomography 8 months after the operation (b)

was then tightly overlaid by the membrane and fixes from the vestibular side (Figure 11). After the flap mobilization, the wound was hermetically closed: an internal U-shaped suture was placed on the periosteum, vestibular and palatal flaps, bringing thereby the wound edges together and pressing additionally the membrane. The flap edges were closed by interrupted and mattress sutures.

8 months after the reconstruction, a repeated computed tomography was performed, dimensions of the regenerate measured (Figure 12). The $3 \mathrm{D}$ model of the bone regenerate was reformed according to the DICOM data and the obtained and planned volumes were compared.

Results and Discussion. To assess the precision of fabricating 3D jaw models and dental membrane templates, bone defect extensions were measured on the tomograms and 3D models produced by the FDM technology. Data of 10 patients were randomly selected for the analysis (Table 1).

The analysis of the measurement results showed sufficiently high precision of the 3D models obtained. Fisher's criterion $\mathrm{F}=0.9923$ signifies the indistinguishability of dispersions. Student's criterion for equal dispersions $\mathrm{t}=0.9715$ also showed that the mean values are statistically indistinguishable. Mean of the modules of the difference between measurement value means was $0.156 \mathrm{~mm}$ at standard deviation of $0.26 \mathrm{~mm}$, which gives in terms of percentage the error of no more than $3.32 \%$.

The source of deviations may be the following factors: measurement errors (a researcher factor); specificity of

Table 1

The results of measuring bone defect extensions on the tomograms and 3D models

\begin{tabular}{|ccccccc}
\hline \multirow{2}{*}{ No. } & \multicolumn{3}{c}{ CT measurement data $(\mathrm{mm})$} & \multicolumn{4}{c}{ 3D model measurements $(\mathrm{mm})$} \\
\hline 1 & The first & The second & The third & The first & The second & The third \\
\hline 2 & 16.07 & 16.16 & 16.10 & 16.30 & 16.55 & 16.37 \\
\hline 3 & 18.48 & 18.87 & 18.77 & 18.25 & 18.10 & 18.19 \\
\hline 4 & 20.09 & 20.21 & 21.97 & 20.50 & 20.58 & 20.87 \\
\hline 5 & 25.79 & 25.82 & 26.01 & 25.78 & 25.82 & 25.79 \\
\hline 6 & 10.09 & 10.06 & 10.72 & 9.89 & 10.01 & 9.96 \\
\hline 7 & 14.92 & 8.89 & 8.58 & 8.90 & 8.76 & 8.86 \\
\hline 8 & 15.95 & 13.98 & 13.79 & 14.01 & 13.85 & 13.90 \\
\hline 9 & 13.17 & 12.96 & 15.71 & 15.85 & 15.72 & 15.81 \\
\hline 10 & 12.57 & 12.49 & 13.01 & 13.10 & 13.05 & 12.97 \\
\hline & & & & 12.35 & 12.43 & 12.40 \\
\hline
\end{tabular}


Table 2

\section{Results of the performed reconstructive operations}

\begin{tabular}{|c|c|c|c|c|}
\hline No. & $\begin{array}{l}\text { The area of reconstruction } \\
\text { and subsequent } \\
\text { implantation }\end{array}$ & $\begin{array}{l}\text { Planned } \\
\text { reconstruction } \\
\text { volume }\left(\mathrm{cm}^{3}\right)\end{array}$ & $\begin{array}{l}\text { Obtained } \\
\text { reconstruction } \\
\text { volume }\left(\mathrm{cm}^{3}\right)\end{array}$ & $\begin{array}{l}\text { Insufficient } \\
\text { bone volume } \\
\left(\mathrm{cm}^{3} / \%\right)\end{array}$ \\
\hline 1 & $\operatorname{UJAP}(2.4,2.5,2.6)$ & 2.19 & 2.13 & $0.06 / 2.67$ \\
\hline 2 & UJAP (2.2) & 0.45 & 0.42 & $0.03 / 6.76$ \\
\hline 3 & APLJ (4.6) & 0.92 & 0.92 & $0.01 / 0.83$ \\
\hline 4 & UJAP $(1.4,1.5,1.6)$ & 2.54 & 2.43 & $0.11 / 4.29$ \\
\hline 5 & UJAP $(2.4,2.5,2.6)$ & 2.12 & 2.05 & $0.08 / 3.64$ \\
\hline 6 & $\operatorname{APLJ}(3.5,3.7)$ & 1.36 & 1.27 & $0.08 / 6.11$ \\
\hline 7 & $\operatorname{APLJ}(3.6,3.7)$ & 1.24 & 1.13 & $0.11 / 8.79$ \\
\hline 8 & $\operatorname{APLJ}(4.6,4.7)$ & 1.47 & 1.39 & $0.07 / 4.88$ \\
\hline 9 & UJAP $(1.3,1.2,2.2)$ & 2.22 & 2.14 & $0.10 / 4.68$ \\
\hline 10 & UJAP $(1.7,1.6,1.5,1.4,1.3)$ & 4.07 & 3.92 & $0.15 / 3.66$ \\
\hline 11 & $\operatorname{ULAP}(2.5,2.6)$ & 1.66 & 1.59 & $0.06 / 3.45$ \\
\hline 12 & UJAP $(1.7,1.6,1.5)$ & 2.94 & 2.85 & $0.10 / 3.32$ \\
\hline 13 & $\operatorname{APLJ}(4.6,4.7)$ & 1.44 & 1.31 & $0.13 / 9.12$ \\
\hline 14 & UJAP (1.2. 1.1) & 1.38 & 1.29 & $0.09 / 6.41$ \\
\hline 15 & APLJ $(3.6,3.7)$ & 1.44 & 1.39 & $0.04 / 2.57$ \\
\hline 16 & APLJ (4.5) & 0.94 & 0.89 & $0.04 / 3.92$ \\
\hline 17 & $\operatorname{APLJ}(3.5,3.6)$ & 1.34 & 1.29 & $0.04 / 2.77$ \\
\hline 18 & UJAP $(1.7,1.6,1.5)$ & 2.41 & 2.30 & $0.11 / 4.64$ \\
\hline 19 & UJAP $(2.6,2.7)$ & 1.23 & 1.11 & $0.12 / 9.70$ \\
\hline 20 & APLJ $(3.5,3.6,3.7)$ & 2.35 & 2.30 & $0.05 / 2.29$ \\
\hline 21 & UJAP (2.2) & 0.59 & 0.48 & $0.12 / 19.91$ \\
\hline 22 & APLJ (4.6) & 0.85 & 0.84 & $0.02 / 1.98$ \\
\hline 23 & APLJ (3.6) & 0.69 & 0.66 & $0.03 / 4.11$ \\
\hline 24 & APLJ $(3.6,3.7)$ & 1.24 & 1.13 & $0.10 / 8.13$ \\
\hline 25 & UJAP $(2.4,2.5,2.6)$ & 3.12 & 2.90 & $0.22 / 7.13$ \\
\hline 26 & APLJ (3.6) & 0.92 & 0.91 & $0.01 / 1.06$ \\
\hline 27 & $\operatorname{APLJ}(3.6,3.7)$ & 1.79 & 1.79 & $0.01 / 0.14$ \\
\hline 28 & APLJ $(3.6,3.7)$ & 1.25 & 1.24 & $0.01 / 0.72$ \\
\hline 29 & APLJ $(4.5,4.6,4.7)$ & 2.86 & 2.73 & $0.12 / 4.30$ \\
\hline 30 & APLJ $(3.4,3.5,3.6)$ & 3.28 & 3.09 & $0.19 / 5.81$ \\
\hline 31 & UJAP $(1.2,1.1)$ & 2.13 & 2.12 & $0.01 / 0.61$ \\
\hline 32 & APLJ $(4.5,4.6)$ & 1.58 & 1.44 & $0.13 / 8.17$ \\
\hline 33 & APLJ (4.6) & 0.79 & 0.67 & $0.12 / 14.85$ \\
\hline 34 & APLJ $(3.6,3.7)$ & 1.74 & 1.69 & $0.04 / 2.53$ \\
\hline \multirow[t]{2}{*}{35} & UJAP $(2.4,2.5)$ & 1.59 & 1.49 & $0.10 / 6.35$ \\
\hline & Mean value & 1.72 & 1.64 & $0.08 / 5.15$ \\
\hline
\end{tabular}

N o t e. UJAP: upper jaw alveolar process; APLJ: alveolar part of the lower jaw. algorithms of 3D model restoration according to the CT results and their transformation into the $3 \mathrm{D}$ model for printing; accuracy of $3 \mathrm{D}$ printer calibration and errors of the FDM.

The results obtained by us are different from the data of Salmi et al. [25], who compare various technologies of 3D prototyping of anatomical skull models by three diverse methods: stereolithography (SLA), powder printing (3DP) and jet 3D printing (PolyJet). PolyJet technology showed the best results in accuracy (the error is $0.18 \pm 0.12 \%)$ compared to SLA $(0.79 \pm 0.26 \%)$ and 3DP $(0.67 \pm 0.43 \%)$. The divergence of our results with their values can be explained by the fact that 3DP and PolyJet printing technologies possess a high accuracy: $0.016 \mathrm{~mm}$ for PolyJet, $0.09 \mathrm{~mm}$ for 3DP. The layer height during SLA printing was $0.15 \mathrm{~mm}$, FDM $-0.1 \mathrm{~mm}$. The divergence can be also explained by the methodology of model measurements and the accuracy of the measuring device. In any case, the error of $3.32 \%$ obtained by us will make $0.86 \mathrm{~mm}$ on conversion to the maximal defect extension of $26 \mathrm{~mm}$, which is permissible in planning the reconstruction of the alveolar bone. Besides, the FDM technology used by us is simpler in printing and requires inexpensive consumable materials compared to the other mentioned methods.

35 patients were treated in compliance with the described method. 20 operations were performed on the lower jaw and 15 on the upper one. In the postoperative period there was partial suture dehiscence above the dental membrane. The wound healed by secondary intention. In other cases no complications were observed.

The time of the operative intervention reduced insignificantly relative to the standard protocol, 5-7 min on average, owing to a quick adaptation of the template-cut dental membrane, which required no fitting. A more important result was a full exclusion of the risk of forming the membranes of smaller size and incorrect shape, which may result in the error when bone reconstruction volume is formed.

Data on the operations performed: reconstruction areas, the volume that was planned and obtained as a result of treatment, and insufficient volume, are presented in Table 2. Lines 7, 21, 33 correspond to the cases with wound dehiscence (marked in bold).

Mean value of the insufficient bone volume was equal to $0.08 \mathrm{~cm}^{3}(0.0541-$ 
$\left.0.2228 \mathrm{~cm}^{3}\right)$ or $5.2 \%(0.3-19 \%)$ of the planned bone volume. Maximal loss of the volume was observed in suture dehiscence and membrane exposure, which occurred in 3 cases of 35 or in $8.57 \%$. In the work of Lizio et al. [26], the efficacy of the alveolar bone volume reconstruction using a titanium mesh as a barrier membrane was evaluated. The results have shown that the loss of bone regenerate volume correlates with the area of the titanium mesh exposure and makes about $30.2 \%$, and the mesh exposure was observed in $80 \%$ of cases (12 of 15). Thus, in regard to the risk of exposure, the resorbable frame membrane compares favorably with the titanium mesh.

Conclusion. The proposed method of computerassisted 3D operation planning and fabrication of intraoperative models for dental membranes using 3D prototyping allows dental surgeons to improve the precision of the guided bone regeneration operations, diminish the intraoperative time of membrane adaptation, and avoid the possibility of its mispositioning. At the same time, the application of the resorbable dental membrane makes it possible to increase the efficacy of the alveolar bone $3 \mathrm{D}$ reconstruction owing to the reduced occurrence of regenerate exposure, and to obtain $94.8 \%$ of the planned bone volume.

Study Funding. The work was supported by the grant of the Russian Scientific Foundation (agreement No.1515-10014 of May 1, 2015)

Conflicts of Interest. The authors have no conflicts of interest to declare. LLC "NEXT" did not finance the study and did not influence the results.

\section{References}

1. Paraskevich V.L. Vozmozhnosti primeneniya vnutrikostnoy implantatsii pri znachitel'noy atrofii chelyustey. V kn.: Materialy I mezhdunarodnoy konferentsii "Aktual'nye voprosy stomatologicheskoy implantatsii" [Possibilities of applying intraosteal implantation in significant jaws atrophy. In: Materials of I International Conference "Actual issues of dental implantation"]. Minsk; 1998; p. 15-23.

2. Ivanov S.Iu., lamurkova N.F., Muraev A.A. Defect elimination of mandible alveolar part by sandwich plastics. Stomatologiia 2010; 89(2): 42-47.

3. Bassett C.A.L. Biologic significance of piezoelectricity. Calcif Tissue Res 1967; 1(1): 252-272, https://doi.org/10.1007/ bf02008098.

4. Boyne P.J., James R.A. Grafting of the maxillary sinus floor with autogenous marrow and bone. J Oral Surg 1980; 38(8): 613-616.

5. Bol'shaya sovetskaya entsiklopediya. T. 30 [Great Soviet encyclopedia. Vol. 30]. Gl. red. Prokhorov A.M. [Prokhorov A.M. (editor)]. Moscow: Sovetskaya entsiklopediya; 1969-1978.

6. Ivanov S.Yu., Yamurkova N.F., Muraev A.A., Khasianov I.T. Evaluating of bone augmentation procedures before dental implants installation. Rossiyskiy vestnik dental'noy implantologii 2013; 2(28): 34-39.

7. Iamurkova N.F., Ivanov S.Iu., Muraev A.A. "Veneer" plastics of jaw alveolar bone before dental implant placement. Stomatologiia 2010; 89(2): 36-41.
8. Panin A.M., Malinetskii G.G., Tsitsiashvili A.M., Anastos A. Mathematical planning of sandwich-plasty by osseous-muco-periosteal advancement flap. Stomatologiia 2013; 92(3): 63-64.

9. Khoury F., Hanser T. Mandibular bone block harvesting from the retromolar region: a 10-year prospective clinical study. Int J Oral Maxillofac Implants 2015; 30(3): 688-697, https://doi. org/10.11607/jomi.4117.

10. Lomakin M.V., Filatova A.S., Soloshchanskii I.I. Guided bone regeneration in the reconstruction of the alveolar bone volume for dental implantation. Rossiyskaya stomatologiya 2011; 4(5): 15-18.

11. Andreeva N.V., Bonartsev A.P., Zharkova I.I., Makhina T.K., Myshkina V.L., Kharitonova E.P., Voinova V.V., Bonartseva G.A., Shaitan K.V., Belyavskii A.V. Culturing of mouse mesenchymal stem cells on poly-3-hydroxybutyrate scaffolds. Bull Exp Biol Med 2015; 159(4): 567-571, https://doi. org/10.1007/s10517-015-3015-5.

12. Bonartsev A.P., Zharkova I.I., Yakovlev S.G., Myshkina V.L., Makhina T.K., Zernov A.L., Kudryashova K.S., Feofanov A.V., Akulina E.A., Ivanova E.V., Zhuikov V.A., Andreeva N.V., Voinova V.V., Bessonov I.V., Kopitsyna M.V., Morozov A.S., Bonartseva G.A., Shaitan K.V., Kirpichnikov M.P. 3D-scaffolds from poly(3-hydroxybutyrate)poly(ethylene glycol) copolymer for tissue engineering. J Biomater Tissue Eng 2016; 6(1): 42-52, https://doi.org/10.1166/jbt.2016.1414.

13. Muraev A.A., Bonartsev A.P., Gazhva Yu.V., Riabova V.M., Volkov A.V., Zharkova I.I., Stamboliev I.A., Kuznetsova E.S., Zhuikov V.A., Myshkina V.L., Mahina T.K., Bonartseva G.A., Yakovlev S.G., Kudryashova K.S., Voinova V.V., Mironov A.A., Shaitan K.V., Gazhva S.I., Ivanov S.Yu. Development and preclinical studies of orthotopic bone implants based on a hybrid construction from poly(3hydroxybutyrate) and sodium alginate. Sovremennye tehnologii v medicine 2016; 8(4): 42-50, https://doi.org/10.17691/ stm2016.8.4.06.

14. Gazhva J.V., Bonartsev A.P., Mukhametshin R.F., Zharkova I.I., Andreeva N.V., Makhina T.K., Myshkina V.L., Bespalova A.E., Zernov A.L., Ryabova V.M., Ivanova E.V., Bonartseva G.A., Mironov A.A., Shaitan K.V., Volkov A.V., Muraev A.A., Ivanov S.Y. In vivo and in vitro development and study of osteoplastic material based on hydroxyapatite, poly-3-hydroxybutyrate and sodium alginate composition. Sovremennye tehnologii v medicine 2014; 6(1): 6-13.

15. Livshits V.A., Bonartsev A.P., Iordanskii A.L., Ivanov E.A., Makhina T.A., Myshkina V.L., Bonartseva G.A. Microspheres based on poly(3-hydroxy)butyrate for prolonged drug release. Polymer Science Series B 2009; 51(7-8): 256263, https://doi.org/10.1134/s1560090409070082.

16. Bonartsev A.P., Bonartseva G.A., Makhina T.K., Myshkina V.L., Luchinina E.S., Livshits V.A., Boskhomdzhiev A.P., Markin V.S., Iordanskii A.L. New poly(3hydroxybutyrate)-based systems for controlled release of dipyridamole and indomethacin. Appl Biochem Microbiol 2006; 42(6): 625-630, https://doi.org/10.1134/s0003683806060159.

17. Ivanov S.Yu., Bonartsev A.P., Gazhva Yu.V., Zharkova I.I., Mukhametshin R.F., Mahina T.K., Myshkina V.L., Bonartseva G.A., Voinova V.V., Andreeva N.V., Akulina E.A., Kharitonova E.S., Shaitan K.V., Muraev A.A. Development and preclinical studies of insulating membranes based on poly-3-hydroxybutyrate-co-3-hydroxyvalerate for guided bone regeneration. Biomeditsinskaya khimiya 2015; 61(6): 717-723. 


\section{ADVANCED RESEARCHES}

18. Bonartsev A.P., Yakovlev S.G., Zharkova I.I., Boskhomdzhiev A.P., Bagrov D.V., Myshkina V.L., Makhina T.K., Kharitonova E.P., Samsonova O.V., Feofanov A.V., Voinova V.V., Zernov A.L., Efremov Y.M., Bonartseva G.A., Shaitan K.V., Kirpichnikov M.P. Cell attachment on poly(3hydroxybutyrate)-poly(ethylene glycol) copolymer produced by Azotobacter chroococcum 7B. BMC Biochem 2013; 14(1): 12, https://doi.org/10.1186/1471-2091-14-12.

19. Bonartsev A.P., Boskhomodgiev A.P., Iordanskii A.L., Bonartseva G.A., Rebrov A.V., Makhina T.K., Myshkina V.L., Yakovlev S.A., Filatova E.A., Ivanov E.A., Bagrov D.V., Zaikov G.E. Hydrolytic degradation of poly(3-hydroxybutyrate), polylactide and their derivatives: kinetics, crystallinity, and surface morphology. Molecular Crystals and Liquid Crystals 2012; 556(1): 288-300, https://doi.org/10.1080/15421406.201 2.635982

20. Boskhomdzhiev A.P., Bonartsev A.P., Makhina T.K., Myshkina V.L., Ivanov E.A., Bagrov D.V., Filatova E.V., Iordanskii A.L., Bonartseva G.A. Biodegradation kinetics of poly(3-hydroxybutyrate)-based biopolymer systems. Biochemistry (Moscow) Supplement Series B: Biomedical Chemistry 2010; 4(2): 177-183, https://doi.org/10.1134/ s1990750810020083.

21. Myshkina V.L., Ivanov E.A., Nikolaeva D.A., Makhina T.K., Bonartsev A.P., Filatova E.V., Ruzhitsky A.O. Bonartseva G.A. Biosynthesis of poly(3-hydroxybutyrate-co3-hydroxyvalerate) copolymer by Azotobacter chroococcum strain 7B. Appl Biochem Microbiol 2010; 46(3): 289-296, https://doi.org/10.1134/s0003683810030075.

22. Bonartsev A.P., Iordanskii A.L., Bonartseva G.A., Zaikov G.E. Biodegradation and medical application of microbial poly (3-hydroxybutyrate). Journal of the Balkan Tribological Association 2008; 14(3): 359-395.

23. Myshkina V.L., Nikolaeva D.A., Makhina T.K., Bonartsev A.P., Bonartseva G.A. Effect of growth conditions on the molecular weight of poly-3-hydroxybutyrate produced by Azotobacter chroococcum 7B. Appl Biochem Microbiol 2008; 44(5): 482-486, https://doi.org/10.1134/ s0003683808050050.

24. Bonartsev A.P., Bonartseva G.A., Shaitan K.V., Kirpichnikov M.P. Poly(3-hydroxybutyrate) and poly(3hydroxybutyrate)-based biopolymer systems. Biochemistry (Moscow) Supplement Series B: Biomedical Chemistry 2011; 5(1): 10-21, https://doi.org/10.1134/s1990750811010045.

25. Salmi M., Paloheimo K.-S., Tuomi J., Wolff J., Mäkitie A. Accuracy of medical models made by additive manufacturing (rapid manufacturing). Journal of Cranio-Maxillofacial Surgery 2013; 41(7): 603-609, https://doi.org/10.1016/j. jcms.2012.11.041.

26. Lizio G., Corinaldesi G., Marchetti C. Alveolar ridge reconstruction with titanium mesh: a three-dimensional evaluation of factors affecting bone augmentation. Int $\mathrm{J}$ Oral Maxillofac Implants 2014; 29(6): 1354-1363, https://doi. org/10.11607/jomi.3417. 